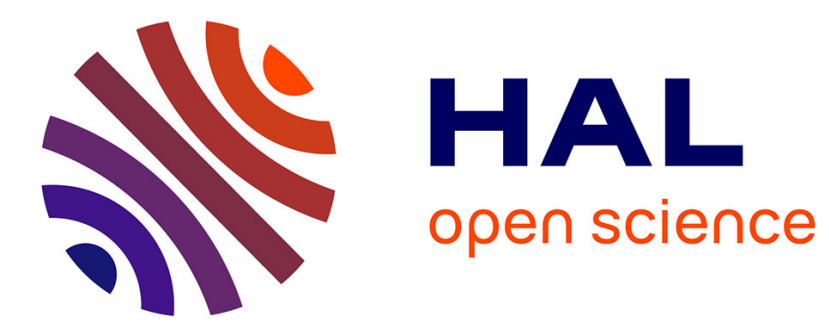

\title{
Association between daily haemodialysis, access to renal transplantation and patients' survival in France
}

Adélaide Pladys, Cécile Vigneau, Maryvonne Hourmant, Gabrielle Duneau, Cécile Couchoud, Sahar Bayat

\section{- To cite this version:}

Adélaide Pladys, Cécile Vigneau, Maryvonne Hourmant, Gabrielle Duneau, Cécile Couchoud, et al.. Association between daily haemodialysis, access to renal transplantation and patients' survival in France. Nephrology, 2018, 23 (3), pp.269-278. 10.1111/nep.12974 . hal-01730200

\section{HAL Id: hal-01730200 \\ https://hal-univ-rennes1.archives-ouvertes.fr/hal-01730200}

Submitted on 8 Jun 2018

HAL is a multi-disciplinary open access archive for the deposit and dissemination of scientific research documents, whether they are published or not. The documents may come from teaching and research institutions in France or abroad, or from public or private research centers.
L'archive ouverte pluridisciplinaire HAL, est destinée au dépôt et à la diffusion de documents scientifiques de niveau recherche, publiés ou non, émanant des établissements d'enseignement et de recherche français ou étrangers, des laboratoires publics ou privés. 


\section{Association between daily hemodialysis, access to renal}

\section{transplantation and patients' survival in France}

Adélaïde Pladys $\mathrm{MSc}^{1-2}$, Cécile Vigneau $\mathrm{MD}-\mathrm{PhD}^{2-3}$, Maryvonne Hourmant $\mathrm{MD}-\mathrm{PhD}^{4}$;

Gabrielle Duneau MD ${ }^{5}$; Cécile Couchoud MD-PhD ${ }^{6}$, Sahar Bayat MD-PhD ${ }^{1}$ on behalf of the REIN registry.

${ }^{1}$ EHESP Rennes, Sorbonne Paris Cité, France; ${ }^{2}$ Université Rennes 1, UMR CNRS 6290,

Rennes, France; ${ }^{3} \mathrm{CHU}$ Pontchaillou, Service de néphrologie, Rennes, France; ${ }^{4} \mathrm{CHU}$ Nantes,

Service de néphrologie, Nantes, France; ${ }^{5} \mathrm{CH}$ Robert Boulin, Service de néphrologie, Libourne, France; ${ }^{6}$ Registre REIN, Agence de la biomédecine, Saint Denis La Plaine, France.

*Corresponding author: Adélaïde Pladys. Département Méthodes Quantitatives en Santé Publique. EHESP, Avenue du Pr. Léon Bernard, 35043 Rennes, France (tel: +33(0)2.99.02.25.35; email address: adelaide.pladys@ehesp.fr)

\section{Running title: Daily hemodialysis in France}

Abstract word count: 246 words

Manuscript word count: 4050 words 


\section{Abstract}

Aim: Daily hemodialysis improves patients' quality of life and blood purification, but its effect on survival remains controversial. The aim of this study was to analyze the association between daily hemodialysis and renal transplantation and survival in France.

Methods: This was an observational cohort study based on the French REIN registry. All incident patients $\geq 18$ y/o who started daily hemodialysis in France between 2003 and 2012 were included. Using a propensity score, 575 patients on daily hemodialysis were matched with 1696 patients receiving thrice-weekly hemodialysis. Survival analysis was performed using the Cox model. Access to the renal transplant waiting list and renal transplantation were analyzed using the Fine and Gray model.

Results: Daily hemodialysis was not independently associated with reduced access to transplant waiting list, whereas, major comorbidities remained associated with restricted waitlisting after multivariate analysis adjusted for confounding factors. After being waitlisted, the cumulative incidence of renal transplantation was lower for the daily hemodialysis than for the thrice-weekly hemodialysis group ( $\mathrm{SHR}=0.72,95 \% \mathrm{CI}$ : $0.56-0.91)$. The risk of death was significantly higher in the daily hemodialysis group $\left(\mathrm{HR}_{\text {adjusted }}=1.58,95 \% \mathrm{CI}\right.$ : 1.4-1.8). Major comorbidities were associated with higher risk of death and lower likelihood of receiving a renal transplant during the follow-up period.

Conclusion: Our study showed that in France, the likelihood of undergoing renal transplantation after being waitlisted was lower for patients on daily hemodialysis than those on thrice-weekly hemodialysis. Moreover, daily hemodialysis was associated with higher risk of death, even after taking into account age and all major comorbidities.

Keywords: daily hemodialysis, end stage renal disease, registry, renal transplantation, survival. 


\section{Introduction}

New dialysis regimens have been developed and tested with the aim of improving the patients' quality of life ${ }^{1,2}$ and blood purification ${ }^{3,4}$. For instance, some authors have shown that increasing the weekly frequency of dialysis sessions is the best regimen to mimic the kidney functional role, compared with hemodialysis (HD) three times/week ${ }^{3,5-7}$. Several studies on daily hemodialysis (DHD) reported the positive effects of increasing the number of HD sessions per week on the control of blood pressure ${ }^{4,8-11}$, uremia ${ }^{3,4}$ and ventricular

hypertrophy ${ }^{9-11}$ in patients with end stage renal disease (ESRD). On the other hand, DHD effects on mortality are less clear-cut. Indeed, some studies reported improved survival associated with $\mathrm{DHD}^{12-15,16}$, while a recent work found that DHD was correlated with increased mortality compared with thrice-weekly $\mathrm{HD}^{17}$. However, the patients included in these studies had neither the same profile (in-center or home dialyzed patients in different physical conditions and often from different countries) ${ }^{12-17}$ nor the same dialysis dose. Moreover, these works did not take into account all major comorbid conditions when assessing survival ${ }^{12-17}$.

In France, the few studies on DHD only investigated the biological effects of switching from HD to DHD. They found that DHD is well tolerated and improves the patients' nutritional status ${ }^{18,19}$ and quality of life ${ }^{19}$. However, the association between DHD and patients' survival has never been investigated in France.

Compared with dialysis, renal transplantation is associated with longer survival ${ }^{20-22}$. However, organ availability is low and cannot cover the increasing demands for kidney transplantation. Daily hemodialysis could be the best choice of renal replacement treatment for patients on the renal transplant waiting list. To our knowledge, the association between DHD and access to renal transplantation has never been investigated. 
Therefore, the aim of this study was to assess the association between DHD and (i) placement on the renal transplant waiting list; (ii) access to renal transplantation after being waitlisted; and (iii) patients' survival, in a large French cohort of patients receiving DHD compared with matched patients treated by standard HD three times/week.
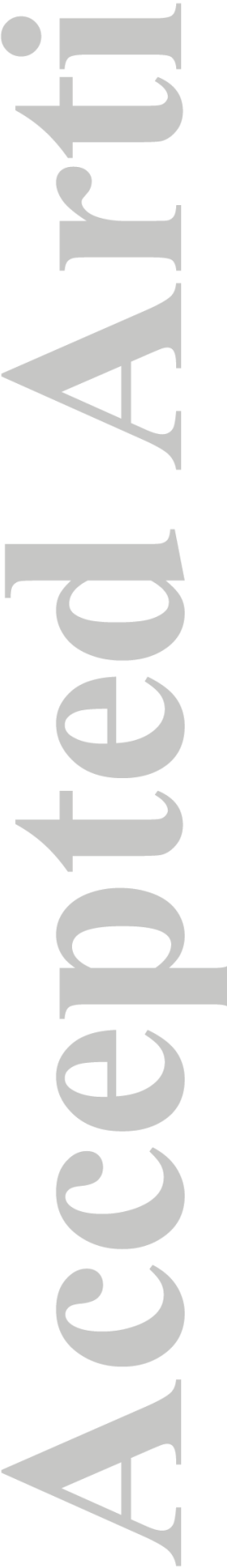


\section{Materials and Methods}

\section{Study population}

Since its establishment in 2002, the Renal Information and Epidemiological Network (REIN) registry intends to include all patients with ESRD who started renal replacement therapy (RRT) in France ${ }^{23}$. For the present study, all incident patients older than 18 years of age who received DHD for at least 30 days between 2003 and 2012 were selected. Short DHD was defined as $\geq 5$ sessions of hemodialysis per week with a duration $\leq 5 \mathrm{~h}$ per session. Nocturnal DHD was not very developed in France before 2012. Moreover, short low-flow DHD was not available in France during the 2003-2012 period. Thus, only patients who received short DHD were included, whereas patients treated with alternative techniques, such as hemofiltration and hemodialfiltration, were excluded. A comparable group was selected among patients who received conventional HD (three sessions/week) for $\geq 30$ days at the same nephrology facility and during the same period as the DHD group.

\section{Data collection}

Three categories of variables were extracted from REIN: i) demographic data: sex and age; ii) baseline bio-clinical data: smoking status (current/former smoker, never-smoker); albumin; hemoglobin; body mass index (BMI); comorbidities: diabetes, active malignancy, hepatic disease, chronic respiratory disease, cardiovascular disease (coronary artery disease, peripheral vascular disease, congestive heart failure, arrhythmia, aortic aneurism and cerebrovascular disease) and walking disability level (autonomous, partially dependent and totally dependent). Blood group (A, O, B and AB) and Panel Reactive Antibody (PRA) level were available for patients placed on the waiting list; and iii) information on the medical follow-up: date of the first DHD or HD; emergency vs planned first dialysis session; starting 
RRT using a catheter; date of placement on the renal transplant waiting list; date of renal transplantation and date of death.

\section{Statistical analysis}

\section{$\underline{\text { Matching procedures }}$}

Three patients on conventional HD were matched to one patient on DHD by dialysis facility, sex, age ( \pm 2 years), year of dialysis initiation ( \pm 2 years) and the logit of the propensity score that indicates the probability of receiving DHD compared with HD $( \pm 0.05)$. The interval between the first dialysis and DHD initiation was also taken into account in the matching procedure. To calculate the propensity score, the logistic regression was performed using diabetes, active malignancy, chronic respiratory disease, cardiovascular diseases and walking disability as variables.

\section{Multiple imputation method}

Values were missing for ten relevant covariates: albumin, hemoglobin and BMI (quantitative variables) as well as smoking status, diabetes, active malignancy, hepatic disease, chronic respiratory disease, cardiovascular disease and walking disability level (categorical variables). Estimate parameters were calculated using the Multiple Imputation by Chained Equations (MICE) procedure ${ }^{24}$. The process was repeated for all variables with missing values and to stabilize the results, the procedure was repeated for ten cycles to produce a single imputed dataset. Finally, the whole procedure was iterated five times to obtain five imputed datasets.

For each event of interest, a new cohort was modeled. Missing data in each dataset were handled by multiple imputations and for the three outcomes, three cohorts and three multiple imputations were produced. 


\section{$\underline{\text { Outcome analysis }}$}

\section{Placement on the renal transplant waiting list}

All patients younger than 80 years of age who started dialysis between 2003 and 2012 were included in the analysis. The outcome of interest was placement on the renal transplant waiting list before December 31, 2013 (endpoint). Patients placed on the renal waiting list before starting dialysis were considered as waitlisted at first dialysis. Death before waitlisting was considered as a competing event and was taken into account in the analysis using the competing risks regression model developed by Fine and Gray ${ }^{25}$. Cumulative incidence curves were also established. Cause-specific hazard ratios were also calculated using a nonparametric Cox model. The patient's follow-up was from the date of first dialysis until the outcome (death, placement on the waiting list or end of follow-up).

\section{Access to renal transplantation after being waitlisted}

All patients younger than 80 years and waitlisted were included in the analysis. Patients who received a renal transplant from a living donor were excluded from this analysis. The outcome of interest was renal transplantation before December 31, 2013. Analyses were performed using the Cox and the Fine and Gray models to take into account the mortality risk before renal transplantation. The patient's follow-up was assessed from the date of placement on the waiting list until the outcome (death, renal transplantation or end of follow-up). Cumulative incidence curves of renal transplantation were also established.

\section{Survival}

All patients who started DHD between 2003 and 2012 were included in the survival analysis. Patient survival was assessed from the date of the first dialysis until death, or December 31, 2013. The Cox model was used to evaluate the association between patients' characteristics 
and death. Renal transplantation was taken into account as a time-varying covariate. Survival Kaplan Meier curves were generated.

All variables associated with each outcome in univariate analysis $(\mathrm{p}<0.2)$ were included in the multivariate model. Results were given as Subdistribution Hazard Ratios (SHR) in the Fine and Gray analyses and as Hazard Ratios (HR) in the Cox analyses with 95\% confidence intervals (CI). A p-value <0.05 was considered statistically significant.

Statistical analyses were performed with the STATA software (version 13.1; College Station, $\mathrm{TX})$

\section{Results}

This study included 575 incident patients who underwent DHD for $\geq 30$ days and 1696 incident patients on HD (3x/week) who were matched to the patients on DHD. The patients' selection procedure with exclusion criteria are provided in Figure 1. The age (mean age: 60.3 \pm 17.3 years for the DHD group; $60.5 \pm 17.2$ years for the $3 \mathrm{x} /$ week HD group) and several baseline characteristics were comparable in the two groups (presence of diabetes, hepatic disease and respiratory disease). However, the proportion of patients with cardiovascular disease, active malignancy or severe walking disabilities was higher in the DHD than in the 3x/week HD group (Table 1).

\section{Placement on the renal transplant waiting list}

By the end of 2013, 774 patients (38\% of the $2039<80$-year-old patients, Table S1) had been placed on the waiting list (176 patients receiving DHD and 598 patients on HD) and $616 / 2039(30.2 \%)$ had died without being waitlisted. The mean dialysis duration before being 
placed on the waiting list was $1.5 \pm 1.7$ years for the DHD group and $1.4 \pm 1.6$ years for the HD group.

Unadjusted analysis (Fine \& Gray model) showed that DHD (SHR=0.83, 95\%CI: 0.71-0.99), old age, all major comorbidities and emergency first dialysis were significantly associated with a lower probability of being waitlisted. In multivariate analysis, DHD was not independently associated with a reduced probability of being waitlisted, whereas all major comorbidities still restricted the access to the waiting list (Table 2, left panel). Similar results were obtained by using the Cox proportional model (HR) (Table 2, right panel).

The probability of being waitlisted after two years of dialysis was approximately $25 \%$ for the DHD group and 30\% for the HD group (Figure 2).

\section{Access to renal transplantation of waitlisted patients}

Waitlisted patients had fewer comorbidities compared with the whole cohorts. Moreover, the characteristics of patients placed on the waiting list at the date of waitlisting were not significantly different between groups, except for age and BMI (Table S2).

Patients who received a renal transplant from a living donor were excluded from the analysis $(\mathrm{n}=28 / 774,3.6 \%)$. Overall, 435/746 $(58.3 \%)$ patients underwent renal transplantation $(\mathrm{n}=88$ DHD, $n=347 \mathrm{HD})$ and 45/746 (6\%) patients died while waiting for a renal transplant. In univariate analyses, patients receiving DHD (SHR=0.74, 95\%CI: 0.58-0.95) had a lower probability of being transplanted than patients on HD (Table 3, left panel). In the multivariate analysis, DHD still restricted the access to transplantation. Similar results were obtained with the Cox model (adjusted HR=0.72, 95\%CI: 0.56-0.91) (Table 3, right panel). However, the effect of age, diabetes and cardiovascular diseases differed according to the used model. 
Overall the cumulative rate of renal transplantation after 2 years on the waiting list was approximately $25 \%$ and $35 \%$ for DHD and HD patients respectively (Figure 3).

\section{Survival}

The mean follow-up was $4.3 \pm 2.7$ years for patients receiving DHD and $4.7 \pm 2.6$ years for patients on HD. During this time, 275/575 (48\%) patients on DHD and 552/1696 (32.5\%) patients on HD died. Causes of death were various among dialyzed patients (Table 4). Respiratory disease was the only cause of death significantly different between groups $(3.6 \%$ for DHD patients vs $1.1 \%$ for HD 3x/week, $\mathrm{p}=0.012$ ).

In unadjusted analyses, DHD (HR=1.6, 95\%CI: 1.4-1.9; Table 5) as well as old age and all major comorbidities significantly increased the risk of death. Conversely, renal transplantation during the follow-up period was associated with a lower risk of death $(\mathrm{HR}=$ $0.20,95 \%$ CI: 0.1-0.3). In the multivariate model, DHD (HR=1.58, 95\%CI: 1.4-1.8), old age and several comorbidities were still associated with a significantly higher risk of death. Renal transplantation during the follow-up ( $\mathrm{HR}=0.5,95 \% \mathrm{CI}$ : $0.3-0.8)$ remained associated with lower risk of death.

Overall, the risk of death after two years of dialysis treatment was approximately $20 \%$ for patients on DHD and 10\% for patients on HD (Figure 4).

As our analysis included patients with missing data using a multiple imputation procedure, we also performed sensitivity analyses restricted to patients with complete data. The results (waitlisting, access to renal transplantation and survival) of the analyses for the group of patients with complete data were consistent with those obtained for all patients after the multiple imputation procedure (data not shown). 


\section{Discussion}

This first French study in which patients on short DHD were compared with matched patients on thrice-weekly HD shows that patients on DHD have a lower chance of access to renal transplantation after being waitlisted and a higher risk of death than patients on thrice-weekly HD. Conversely, this dialysis modality was not independently associated with a reduced access to the renal transplant waiting list.

In our study, unadjusted analysis indicated that the probability of being placed on the renal transplant waiting list was lower for patients receiving DHD. However, the association between DHD and waitlisting remained not statistically significant after the adjustment. This is the first study that analyzed the association between short DHD and access to renal transplant waiting list; therefore, we cannot compare our results with previous findings. Nevertheless, our data confirm the association between old age and restricted access to the renal transplant waiting list $\mathrm{t}^{22,26,27}$.

The probability of renal transplantation for waitlisted patients was lower in the DHD group than in the thrice-weekly HD group (SHR=0.74, 95\%CI: 0.57-0.96). In addition, having $>2$ cardiovascular diseases and PRA $\geq 80 \%$ were also associated with a lower chance of being transplanted, differently from the blood groups $\mathrm{A}$ and $\mathrm{AB}$ (compared with $\mathrm{O}$ ). The negative effect of DHD on the probability of renal transplantation cannot be explained by the French rules on the allocation of organs from deceased donors. These rules take into account HLA matching, age adequacy between donor and recipient and time on the waiting list, but not the patient's clinical characteristics or dialysis modalities. A more in-depth study should be done to determine whether waitlisted patients who receive DHD refuse more often an organ proposition, or are more often on temporary inactive status for any other reason. 
Like Suri et al, ${ }^{17}$ we found that DHD was not associated with a survival benefit. These authors included only in-center dialyzed patients from the International Quotidian Dialysis Registry (IQDR), among whom there were many French patients (68\%). They matched patients on DHD with patients who received 3x/week HD from the Dialysis Outcomes and Practice Patterns Study (DOPPS). Unlike Suri et al, we took into account more comorbidities and matched patients on DHD with patients on HD (3 times/week) from the same dialysis facility. Other studies reported improved survival for patients who received DHD ${ }^{14,15,28,29}$, but included only patients undergoing DHD at home. In some of these works, patients were compared with patients who received conventional in-center $\mathrm{HD}^{14,15}$. Moreover, patients dialyzed at home are generally healthier and younger than patients treated in-center ${ }^{16,28,29}$. This might explain the better survival observed among patients who receive DHD at home $\mathrm{e}^{14,16}$, as it has been recently discussed by Labriola et $a{ }^{30}$. Indeed, these authors highlighted the problem of selection bias and of indication bias in retrospective registry studies. For this reason, and due to the fact that studies from the Frequent Hemodialysis Network were under-powered, they argued that the development of frequent HD regimens should not be based on the results of these survival studies. Nevertheless, the increase frequency of hemodialysis sessions per week might cause biological disorders and influence patients' survival. Indeed, as mentioned by Suri et al, increased removal of vitamins might cause malnutrition. In addition, increased HD sessions might disorder molecules (potassium, phosphate) balances and also increase cardiovascular complications ${ }^{17}$.

In our study, patients were mainly dialyzed in-center (70\%); however, we also included some patients dialyzed at home $(6 \%)$ or in a satellite unit (24\%). In the previous survival studies, beside the variety of dialysis environments, the populations under study were heterogeneous and patients receiving DHD were not always comparable with patients receiving conventional thrice-weekly $\mathrm{HD}^{12,13,16}$. Finally, in our study, and differently from others ${ }^{12-}$ 
14,28,29, we selected patients who had been treated with dialysis for at least 30 days to avoid the inclusion of patients who received only a few dialysis sessions and/or of patients who died early.

We hypothesize that DHD indications might be different in France than in other countries and this might explain the difference in mortality. The implementation of new short low-flow DHD at home is slowly progressing in France since 2012. Several studies showed that DHD has a positive effect on the patients' quality of life $\mathrm{e}^{10-12,18,31}$. In the future, the development of new machines for short low-flow DHD at home might modify the negative association between DHD and survival. In the United States, low-flow short DHD at home has been in use for several years and the patients' biological parameters have been assessed in a few studies after initiation of such a treatment ${ }^{32,33}$. Kraus et al, observed decreased blood pressure after switching from conventional HD to short DHD with low-flow machines ${ }^{33}$. In addition, such patients could reduce the antihypertensive drug intake and showed lower creatinine, albumin and hemoglobin values. Kohn et al, reported better phosphorous and urea removal associated with short DHD compared with conventional HD or peritoneal dialysis. The authors suggested that this dialysis modality improves toxin clearance and decreases morbidity and mortality.

The strength of our study is the inclusion of a large unbiased population-based cohort that allowed us to analyze DHD association with access to renal transplant waiting list, renal transplantation and survival. Indeed, previous French studies on DHD included only small numbers of patients and focused on the quality of life or nutritional benefits ${ }^{18,19}$. Thanks to the REIN registry, we could include all patients who received DHD for at least 30 days in France between 2003 and 2012 and we could select controls within the same facility to take into account the different medical practice profiles. Moreover, we included all major comorbidities and we used the Fine and Gray model to take into account competing risks. 
Our study has several limitations. This is an observational study and a hidden bias due to latent variables may remain despite the matching procedure. The medical reasons explaining the nephrologist's decisions to start or to switch to DHD were not recorded in the REIN registry. These missing variables could help understanding the lower survival of French patients on DHD. Moreover, data on the kt/V doses were often missing in the REIN registry and therefore, we could not determine whether patients on DHD received an appropriate dialysis dose per week. We included all major comorbidities present in the REIN registry in our study; however, it was very difficult to match patients for each comorbid condition. Therefore, we chose to use the propensity score measuring a global score of clinical risks Despite the matching procedure, the rates of cardiovascular disease, walking disabilities and active malignancy repartitions were different between the DHD and HD groups. In addition, our study focused on the effect of DHD performed for at least one month, but did not take into account the complete treatment trajectory of each patient.

Finally, as this study focused on patients on short DHD, our results cannot be generalized to patients on long, nocturnal home HD.

In conclusion, our study shows that French patients on short DHD have a lower chance of renal transplantation after being waitlisted and higher risk of death compared with matched patients on thrice-weekly HD. Even after taking into account all patients' characteristics, our study did not allow understanding why DHD is associated with higher risk of death in this population. Additional studies on the treatment trajectories of French patients who receive DHD might allow better assessing the association between survival and dialysis history.

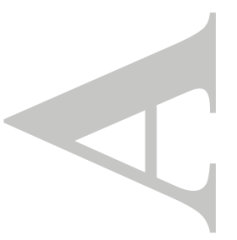




\section{Acknowledgments}

This study was supported by grants from the French Biomedicine Agency. We would like to acknowledge all REIN registry participants, including the professionals who collected the data. We thank Elisabetta Andermarcher for English revisions

\section{Ethics approval and consent to participate}

Subjects involved in our study were extracted from the French REIN registry which received the agreement from the CNIL (Commission Nationale de l'Information et des Libertés) in 2010 (agreement number: 903188 Version 3). Verbal informed consent to participate was obtained from all subjects involved. This study approved by the French Biomedecine Agency included patients' information anonymized and de-identified directly in the database and before the extraction for analysis.

\section{Conflict of interests}

The authors declare that they have no conflict of interests.

\section{References}

1. Punal J, Lema LV, Sanhez-Guisande D, Ruano-Ravina A. Clinical effectiveness and quality of life of conventional hemodialysis versus short daily hemodialysis: a systematic review. Nephrol Dial Transplant. 2008; 23: 2634-2646.

2. Vos PF, Zilch O, Kooistra MP. Clinical Outcome of Daily Dialysis. Am J of Kidney Dis. 2001; 37 (1): 99-102.

3. Bonomini V, Mioli V, Albertazzi A, Scolari P. Daily-dialysis programme: indications and results. Nephrol Dial Transplant. 1998; 13(11): 2774-7. 
4. Kjellstrand CM, Ing T. Daily Hemodialysis: History and Revival of a Superior Dialysis Method. ASAIO Journal. 1998; 117-122.

5. Kjellstrand CM, Evans RL, Petersen RJ, Shideman JR, Hartitzsch B von, Buselmeier TJ. The « unphysiology » of dialysis: A major cause of dialysis side effects? Hemodialysis International. 2004; 8(1):24-9.

6. Toussaint ND. Review: Differences in prescription between conventional and alternative haemodialysis. Nephrology. 2010; 15: 399-405.

7. Pierratos A, Ouwendyk M, Francoeur R et al. Nocturnal hemodialysis: three-year experience. J Am Soc Nephrol. 1998; 9(5): 859-68.

8. Blagg CR, Ing TS, Berry D, Kjellstrand CM. The History and Rationale of Daily and Nightly Hemodialysis. Contrib Nephrol. 2004; 145: 1-9.

9. Culleton BF, Asola MR. The impact of short daily and nocturnal hemodialysis on quality of life, cardiovascular risk and survival. Journal of Nephrology. 2011; 24(4): 405-415.

10. Locatelli F, Buoncristiani U, Canaud B, Köhler H, Petitclerc T, Zucchelli P. Dialysis dose and frequency. Nephrol Dial Transplant. 2005; 20(2): 285-96.

11. Lindsay R, Nesrallah G, Suri R, Garg A, Moist L. Is more frequent hemodialysis beneficial and what is the evidence? Current Opinion in Nephrology \& Hypertension. 2004; 13(6): 631-635.

12. Kjellstrand CM, Buoncristiani U, Ting G et al. Short daily haemodialysis: survival in 415 patients treated for 1006 patients-years. Nephrol Dial Transplant. 2008; 23: 3283-3289.

13. Kjellstrand CM, Buoncristiani U, Ting G et al. Survival with short-daily hemodialysis: Association of time, site, and dose of dialysis. Hemodialysis Int. 2010; 14: 464-470. 
14. Nesrallah GE, Lindsay RM, Cuerden MS et al. Intensive Hemodialysis Associates with Improved Survival Compared with Conventional Hemodialysis. J Am Soc Nephrol. 2012; 23: 696-705.

15. Johansen KL, Zhang R, Huang Y et al. Survival and hospitalization among patients using nocturnal and short daily compared to conventional hemodialysis: a USRDS study. Kidney Int. 2009; 76: 984-990.

16. Woods JD, Port FK, Orzoi S et al. Superior patient and technique survival with very high standard Kt/V in quotidian home hemodialysis. Kidney Int. 1999; 55: 2467-2476.

17. Suri RS, Lindsay RM, Bieber BA et al. A multivariate cohort study of in-center daily hemodialysis and patient survival. Kidney Int. 2013; 83: 300-307.

18. Traeger J, Galland R, Delawari E, Arkouche W, Hadden R. Six years' experience with short daily hemodialysis: Do the early improvements persist in the mid and long term? Hemo Int. 2004; 8: 151-158.

19. Galland R, Traeger J, Arkouche W, Cleaud C, Delawari E, Fouque D. Short daily hemodialysis improves nutritional status in hemodialysis patients. Kidney Int. 2001; 60: $1555-1600$.

20. Wolfe RA, Ashby VB, Milford EL et al. Comparison of mortality in all patients on dialysis, patients on dialysis awaiting transplantation, and recipients. The New England J of Med. 1999; 341(23): 1725-1730.

21. Rabbat CG, Thorpe KE, Russell JD, Churchill DN. Comparison of mortality risk for dialysis patients and cadaveric first renal transplant recipients in Ontario, Canada. $J$ Am Soc Nephrol. 2000; 11: 917-922.

22. Oniscu GC, Schalkwijk AH, Johnson RJ, Brown H, Forsythe JLR. Equity of access to renal transplant waiting list and renal transplantation in Scotland: cohort study. British Med J. 2003; 327: 1-5. 
23. Couchoud C, Stengel B, Landais P et al. The renal epidemiology and information network (REIN): a new registry for end stage renal disease in France. Nephrol Dial Transplant. 2006; 21: 411-418.

24. Sterne JAC, White IR, Carlin JB et al. Multiple imputation for missing data in epidemiological and clinical research: potential and pitfalls. British Med J. 2009; 338: 1-
12.

25. Fine JP, Gray RJ. A proportional hazards model for the subdistribution of a competing risk. J Am Stat Association. 1999; 94(446) 496-509.

26. Bayat S, Macher MA, Couchoud C et al. Individual and regional factors of access to the renal transplant waiting list in France in a cohort of dialyzed patients. Am J of Transplant. $2015 ; 15: 1050-1060$.

27. Satayathum S, Pisoni RL, McCullough KP et al. Kidney transplantation and wait-listing rates from the international Dialysis Outcomes and Practices Patterns Study (DOPPS). Kidney Int. 2005; 68: 330-337.

28. Weinhandl ED, Liu J, Gilbertson DT, Arneson TJ, Collins AJ. Survival in daily home hemodialysis and matched thrice-weekly in-center hemodialysis patients. J Am Soc Nephrol. 2012; 23: 895-904.

29. Weinhandl ED, Gilbertson DT, Collins AJ. Mortality, hospitalization, and technique failure in daily home hemodialysis and matched peritoneal dialysis patients: a matched cohort study. Am J Kidney Dis. 2016; 67(1):98-110.

30. Labriola L, Morelle J, Jadoul M. Con: Frequent haemodialysis for all chronic haemodialysis patients. Nephrol Dial Transplant. 2015; 30: 23-27.

31. Naso A, Scarparrotta G, Naso El, Calo LA. Intensive home hemodialysis: an eye at the past looking for the hemodialysis of the future. Artificial Organs. 2015; 39(9): 736-740. 
32. Kohn O, Coe F, Ing T. Solute kinetics with short-daily home hemodialysis using slow dialysate flow rate. Hemodial Int. 2010; 14:39-46

33. Kraus M, Burkart J, Hegeman R, Solomon R, Coplon N, Moran J. A comparison of center-based vs. home-based daily hemodialysis for patients with end-stage renal disease. Hemodial Int. 2007; 11:468-477.
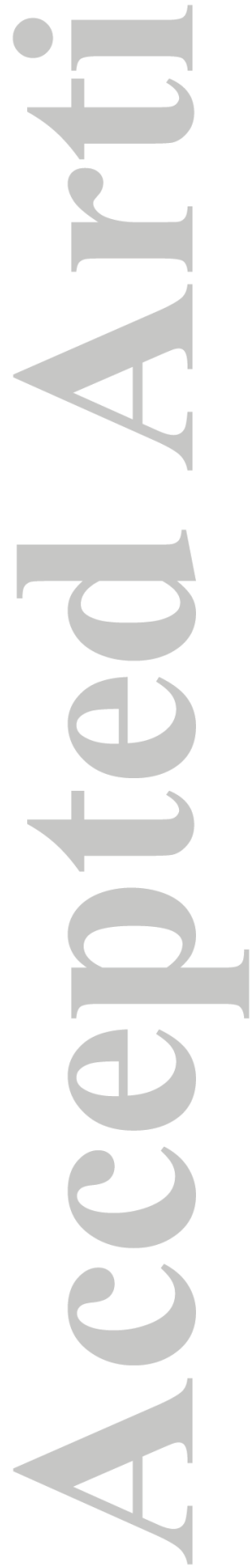


\section{Figure legends}

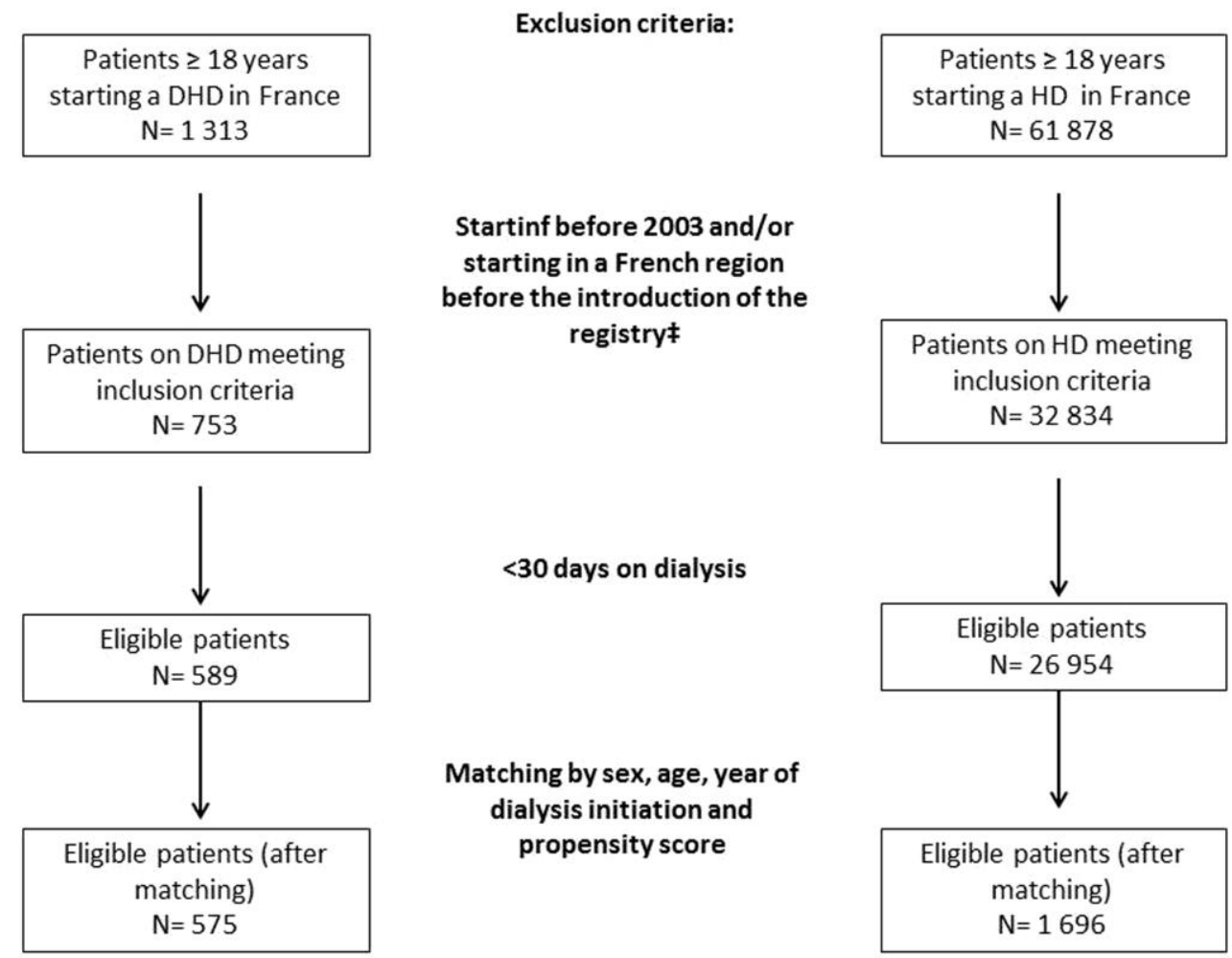

Figure 1. Flow chart showing the study cohort selection and the eligible patients. $\ddagger$ As the REIN registry was established in France in 2002 and has been integrating progressively all French regions, we decided to exclude patients who started dialysis before the introduction of the registry in their region.

Figure 1. Flow chart showing the study cohort selection and the eligible patients. $\$$ As the REIN registry was established in France in 2002 and has been integrating progressively all French regions, we decided to exclude patients who started dialysis before the introduction of the registry in their region. 


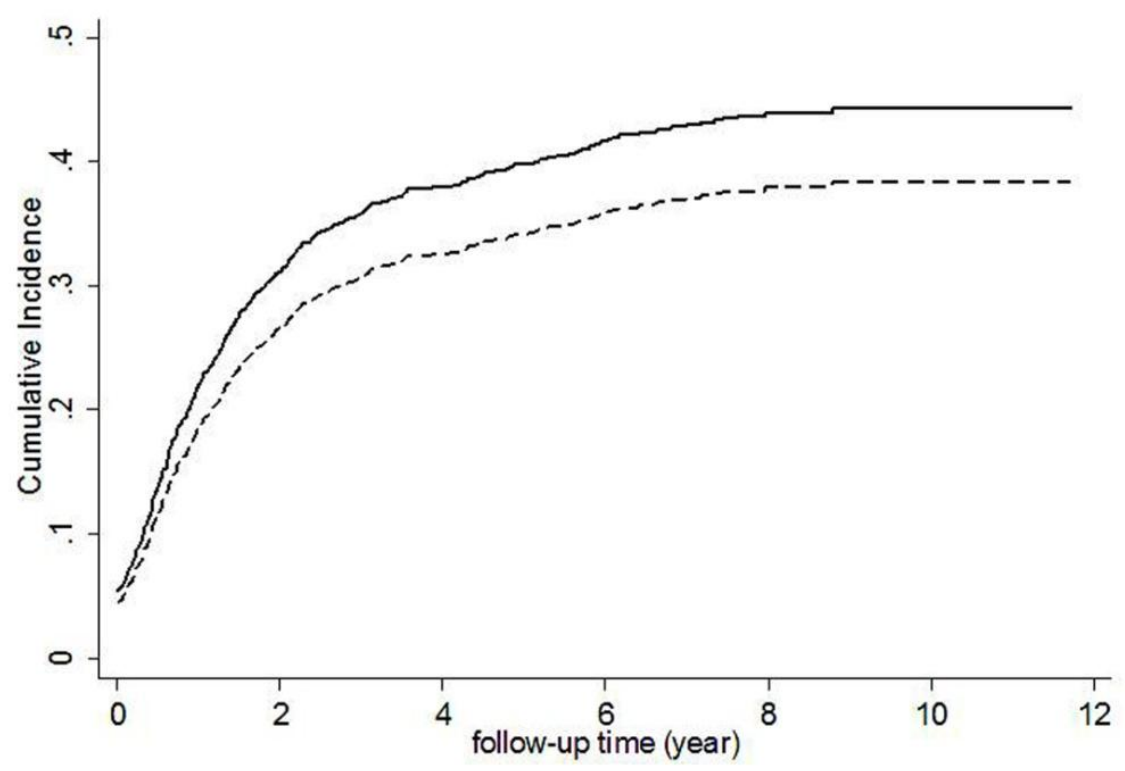

Figure 2. Crude Cumulative Incidence Function (CIF) for waitlisting, in patients $<80$ years $(n=2039)$ by treatment group: DHD (dotted line) and thrice-weekly HD (solid line).

Figure 2. Crude Cumulative Incidence Function (CIF) for waitlisting, in patients $<80$ years ( $\mathrm{n}=2039)$ by treatment group: DHD (dotted line) and thrice-weekly HD (solid line). 


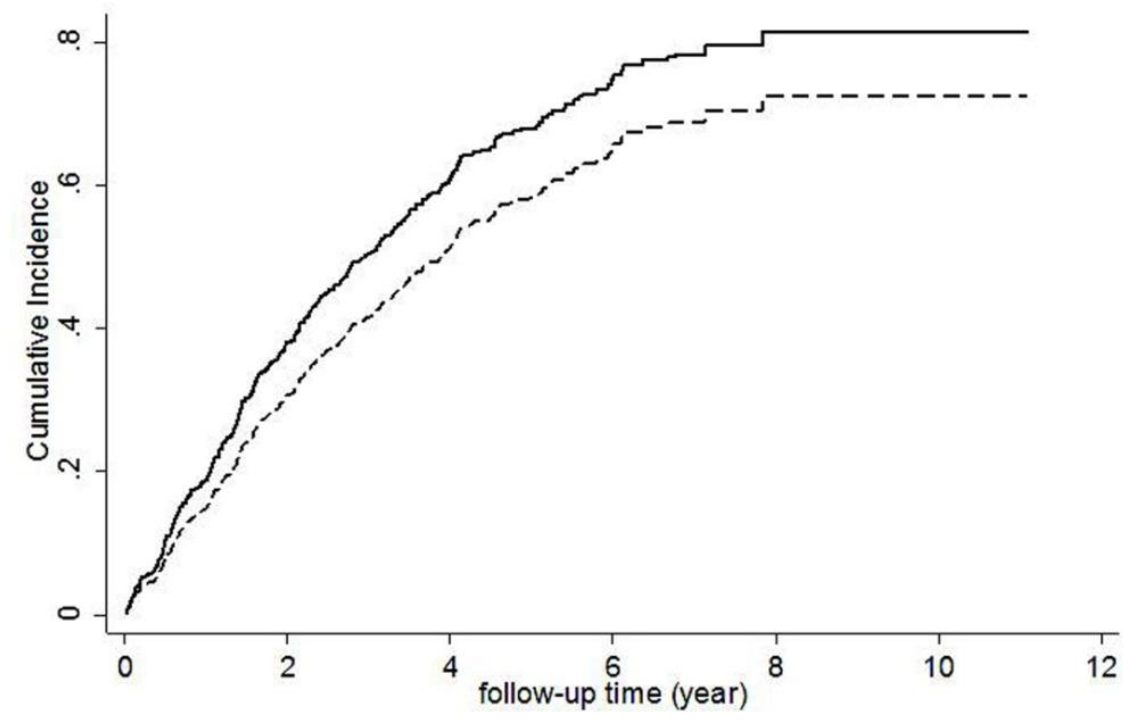

Figure 3. Crude CIF for access to renal transplantation after being waitlisted, in patients $<80$ years ( $n=746$ ) by treatment group: DHD (dotted line) and thrice-weekly HD (solid line).

Figure 3. Crude CIF for access to renal transplantation after being waitlisted, in patients $<80$ years ( $\mathrm{n}=746)$ by treatment group: DHD (dotted line) and thrice-weekly HD (solid line). 


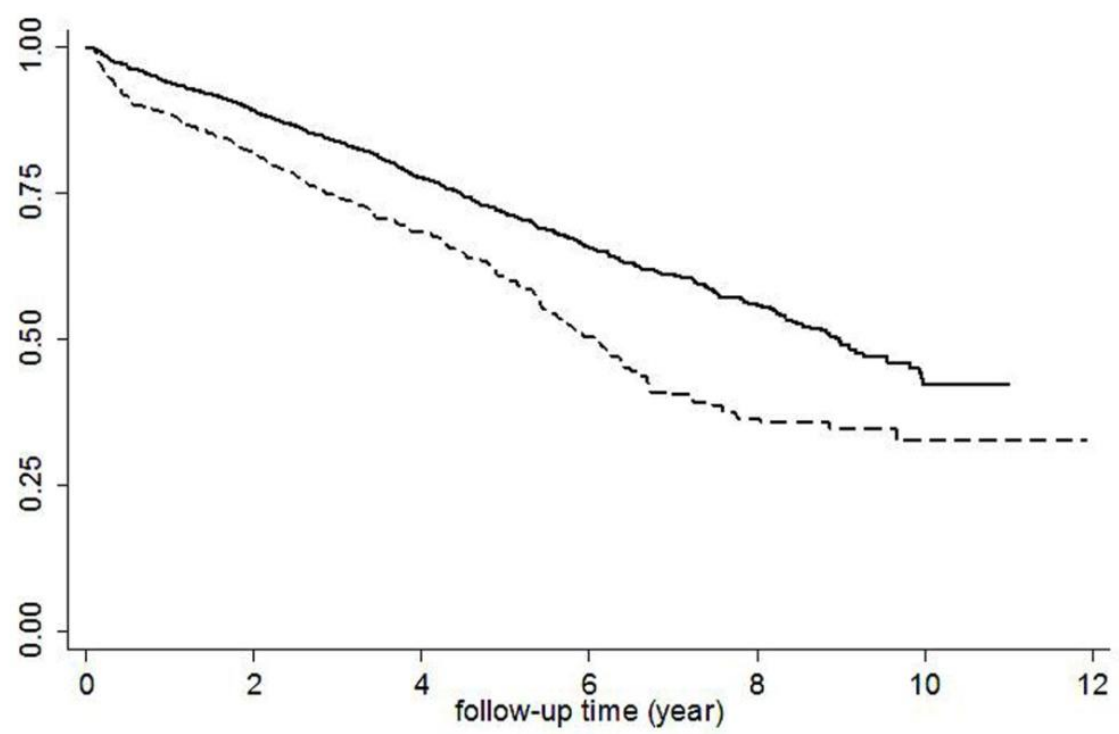

Figure 4. Crude survival curves in the whole cohorts $(n=2271)$ by treatment group: $D H D$ (dotted line $)$ and thrice-weekly HD (solid line).

Figure 4. Crude Kaplan Meier survival curves in the whole cohorts $(n=2271)$ by treatment group: DHD (dotted line) and thrice-weekly HD (solid line).

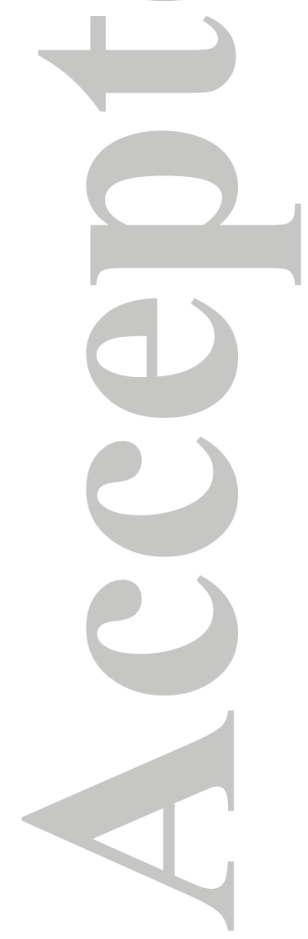




\section{Tables}

Table 1. Baseline characteristics of the general population on HD 3x/week $(n=32834)$ and in matched patients' groups (DHD and thrice-weekly HD, $\mathrm{n}=2271$ )

\begin{tabular}{|c|c|c|c|c|c|}
\hline & $\begin{array}{c}\text { General population* } \\
\text { on HD } 3 x / \text { week } \\
\begin{array}{c}(n=32834) \\
n(\%)\end{array}\end{array}$ & $\begin{array}{l}\text { HD 3x/week } \\
\begin{array}{c}(n=1696) \\
\text { n }(\%)\end{array}\end{array}$ & $\begin{array}{c}\text { Matched pa } \\
\text { DHD } \\
(\mathbf{n}=575) \\
n(\%)\end{array}$ & ents & $\begin{array}{c}\text { Missing } \\
(\%)\end{array}$ \\
\hline Sex & & & & 0.9 & 0.0 \\
\hline Men & $20735(63.2)$ & 1067 (62.9) & $361(62.8)$ & & \\
\hline Women & $12099(36.8)$ & $629(37.1)$ & $214(37.2)$ & & \\
\hline Age (years) & & & & 0.9 & 0.0 \\
\hline $18-45$ & $3201(9.7)$ & 334 (19.7) & $114(19.8)$ & & \\
\hline $45-60$ & $6076(18.5)$ & $444(26.2)$ & $153(26.6)$ & & \\
\hline $60-75$ & $11350(34.6)$ & 507 (29.9) & $170(29.6)$ & & \\
\hline$\geq 75$ & $12207(37.2)$ & $411(24.2)$ & $138(24)$ & & \\
\hline Smoking status & & & & 0.3 & 12.7 \\
\hline Current/Former smoker & $11303(34.4)$ & $613(36)$ & $228(39.7)$ & & \\
\hline Never smoker & $16699(50.9)$ & $867(51)$ & $275(47.8)$ & & \\
\hline Albumin (g/dl) & & & & $<0.001$ & 24.3 \\
\hline$<30$ & $5616(17.1)$ & $245(14.4)$ & $119(20.7)$ & & \\
\hline$\geq 30$ & $19589(59.7)$ & $1006(59.3)$ & $350(61)$ & & \\
\hline Hemoglobin (g/dl) & & & & 0.054 & 10.4 \\
\hline$<10$ & $15185(46.2)$ & $755(44.5)$ & $245(42.6)$ & & \\
\hline $10-12$ & $9573(29.2)$ & $485(28.6)$ & $168(29.2)$ & & \\
\hline$>12$ & $4746(14.5)$ & $268(15.8)$ & $114(19.8)$ & & \\
\hline BMI $\left(\mathbf{k g} / \mathbf{m}^{2}\right)^{\mathbb{I}}$ & & & & $<0.001$ & 23 \\
\hline$<18.5$ & $1282(3.9)$ & $72(4.2)$ & $29(5)$ & & \\
\hline $18.5-23$ & $6598(20.1)$ & $310(18.3)$ & $122(21.2)$ & & \\
\hline $23-25$ & $4116(12.5)$ & $200(11.8)$ & $74(12.9)$ & & \\
\hline$\geq 25$ & $12720(38.7)$ & $683(40.3)$ & $260(45.2)$ & & \\
\hline Diabetes & & & & 0.2 & 1.3 \\
\hline Yes & $12960(39.5)$ & $576(34)$ & $217(37.7)$ & & \\
\hline No & $19396(59.1)$ & $1099(64.8)$ & $349(60.7)$ & & \\
\hline Hepatic disease & & & & 0.96 & 2.6 \\
\hline Yes & $836(2.5)$ & $35(2.1)$ & $13(2.3)$ & & \\
\hline No & $31020(94.5)$ & $1617(95.3)$ & $547(95)$ & & \\
\hline Active malignancy $^{\dagger}$ & & & & 0.03 & 2.4 \\
\hline Yes & $3561(10.8)$ & $130(7.7)$ & $64(11)$ & & \\
\hline No & $28320(86.3)$ & $1527(90)$ & $495(86)$ & & \\
\hline Respiratory disease & & & & 0.07 & 7.5 \\
\hline Yes & $3859(11.8)$ & $154(9.1)$ & $71(12.3)$ & & \\
\hline No & $27954(85.1)$ & $1527(88.2)$ & $487(84.7)$ & & \\
\hline Cardiovascular diseases ${ }^{\dagger}$ & & & & $<0.001$ & 0.0 \\
\hline 0 & $14947(45.5)$ & $932(55)$ & $275(47.8)$ & & \\
\hline 1 & $7470(22.8)$ & $371(22)$ & $112(19.5)$ & & \\
\hline 2 & $5098(15.5)$ & $204(12)$ & $76(13.2)$ & & \\
\hline$>2$ & $5319(16.2)$ & $189(11)$ & $112(19.5)$ & & \\
\hline Walking disability & & & & $<0.001$ & 15.5 \\
\hline Autonomous & $22064(67.2)$ & $1233(72.7)$ & $400(69.6)$ & & \\
\hline Totally dependent & $1655(5)$ & $44(2.6)$ & $41(7)$ & & \\
\hline Partially dependent & $3850(11.7)$ & $146(8.6)$ & $54(9.4)$ & & \\
\hline
\end{tabular}

*General population: all incident patients who initiated 3x/week HD in a French REIN region between 2003 and 2012. "IBMI: Body Mass Index; ${ }^{\dagger}$ Active malignancy: solid tumors or hematological malignancies; ${ }^{\ddagger}$ Cardiovascular diseases: myocardial infarction, arrhythmias, coronary insufficiency, heart failure, arteritis of the lower limbs, cerebrovascular accident. Missing data are stated in an additional column. 
Table 2. Factors associated with access to the renal transplant waiting list (subdistribution hazard and cause-specific approaches, $\mathbf{n = 2 0 3 9 )}$

\begin{tabular}{|c|c|c|c|c|}
\hline \multirow[b]{2}{*}{ Variable } & \multicolumn{2}{|c|}{ SHR* $(95 \% \mathrm{CI})$} & \multicolumn{2}{|c|}{ Cause-specific HR $* *(95 \% \mathrm{CI})$} \\
\hline & Unadjusted & Adjusted & Unadjusted & Adjusted \\
\hline \multicolumn{5}{|l|}{ Sex (vs Men) } \\
\hline Women & $0.97(0.84-1.13)$ & $0.91(0.79-1.06)$ & $0.98(0.85-1.14)$ & $0.93(0.8-1.09)$ \\
\hline \multicolumn{5}{|l|}{ Age (vs 18-39) } \\
\hline $40-59$ & $0.54(0.46-0.62)$ & $0.69(0.58-0.81)$ & $0.56(0.48-0.66)$ & $0.70(0.6-0.83)$ \\
\hline $60-69$ & $0.20(0.15-0.25)$ & $0.30(0.23-0.39)$ & $0.22(0.17-0.27)$ & $0.31(0.24-0.40)$ \\
\hline $70-80$ & $0.02(0.01-0.04)$ & $0.03(0.02-0.06)$ & $0.03(0.02-0.04)$ & $0.04(0.02-0.06)$ \\
\hline \multicolumn{5}{|c|}{ Smoking status (vs Never smoker) } \\
\hline Current/Former smoker & $0.85(0.73-0.99)$ & - & $0.86(0.74-1.005)$ & - \\
\hline \multicolumn{5}{|l|}{ Albumin (vs $\geq 30 \mathrm{~g} / \mathrm{dl})$} \\
\hline$<30$ & $0.85(0.66-1.08)$ & - & $0.92(0.72-1.18)$ & - \\
\hline \multicolumn{5}{|l|}{ Hemoglobin (vs 10-12 g/dl) } \\
\hline$<10$ & $0.97(0.82-1.14)$ & - & $0.96(0.82-1.13)$ & - \\
\hline$>12$ & $1.01(0.80-1.27)$ & - & $0.98(0.77-1.23)$ & - \\
\hline \multicolumn{5}{|l|}{ BMI (vs $\left.23-25 \mathrm{~kg} / \mathrm{m}^{2}\right)^{\mathbb{I}}$} \\
\hline$<18.5$ & $1.01(0.72-1.40)$ & - & $1.11(0.78-1.56)$ & - \\
\hline $18.5-23$ & $1.02(0.79-1.32)$ & - & $1.06(0.81-1.38)$ & - \\
\hline$\geq 25$ & $0.69(0.54-0.88)$ & - & $0.70(0.55-0.90)$ & - \\
\hline \multicolumn{5}{|l|}{ Diabetes (vs No) } \\
\hline Yes & $0.40(0.34-0.48)$ & $0.69(0.58-0.83)$ & $0.41(0.35-0.49)$ & $0.7(0.58-0.84)$ \\
\hline \multicolumn{5}{|l|}{ Cirrhosis (vs No) } \\
\hline Yes & $0.22(0.09-0.52)$ & $0.21(0.09-0.50)$ & $0.28(0.12-0.69)$ & $0.25(0.10-0.60)$ \\
\hline \multicolumn{5}{|l|}{ Active malignancy (vs No) ${ }^{\dagger}$} \\
\hline & $0.42(0.29-0.60)$ & $0.52(0.37-0.74)$ & $0.46(0.32-0.67)$ & $0.57(0.40-0.83)$ \\
\hline \multicolumn{5}{|l|}{ Respiratory disease (vs No) } \\
\hline Yes & $0.35(0.24-0.50)$ & $0.52(0.36-0.76)$ & $0.37(0.26-0.53)$ & $0.53(0.36-0.77)$ \\
\hline \multicolumn{5}{|c|}{ Cardiovascular diseases (vs 0$)^{\ddagger}$} \\
\hline 1 & $0.42(0.34-0.52)$ & $0.66(0.54-0.82)$ & $0.43(0.35-0.53)$ & $0.67(0.54-0.98)$ \\
\hline 2 & $0.35(0.27-0.47)$ & $0.71(0.53-0.95)$ & $0.38(0.29-0.50)$ & $0.73(0.54-0.98)$ \\
\hline$>2$ & $0.19(0.14-0.27)$ & $0.53(0.37-0.75)$ & $0.22(0.16-0.31)$ & $0.56(0.39-0.81)$ \\
\hline \multicolumn{5}{|c|}{ Walking disability (vs Autonomy) } \\
\hline Totally dependent & $0.17(0.08-0.39)$ & $0.25(0.11-0.54)$ & $0.22(0.098-0.49)$ & $0.28(0.13-0.61)$ \\
\hline Partially dependent & $0.21(0.13-0.33)$ & $0.38(0.24-0.59)$ & $0.23(0.14-0.38)$ & $0.41(0.26-0.66)$ \\
\hline \multicolumn{5}{|l|}{ Treatment (vs HD 3x/week) } \\
\hline DHD & $0.83(0.71-0.99)$ & - & $0.90(0.76-1.07)$ & - \\
\hline \multicolumn{5}{|c|}{ Starting RRT with a catheter (vs No) } \\
\hline Yes & $0.87(0.75-1.01)$ & - & $0.91(0.78-1.06)$ & - \\
\hline \multicolumn{5}{|c|}{ Emergency $1^{\text {st }}$ dialysis session (vs No) } \\
\hline Yes & $0.87(0.75-1.01)$ & $0.8(0.68-0.93)$ & $0.85(0.73-0.99)$ & $0.79(0.67-0.93)$ \\
\hline
\end{tabular}

All variables included in multivariate models are presented in the table with the relative HR or SHR and 95\%CI; *SHR:

Subdistribution Hazard Ratio; **HR: Hazard Ratio; ${ }^{\mathbb{I}} \mathrm{BMI}$ : Body Mass Index; ${ }^{\dagger}$ Active malignancy: solid tumors or hematological malignancies; ${ }^{\ddagger}$ Cardiovascular Disease: myocardial infarction, arrhythmias, coronary insufficiency, heart failure, arteritis of the lower limbs, cerebrovascular accident; ${ }^{¥} \mathrm{RRT}$ : Renal Replacement Therapy. 
Table 3. Factors associated with renal transplantation in waitlisted patients (subdistribution hazard and cause-specific approaches, $n=746$ )

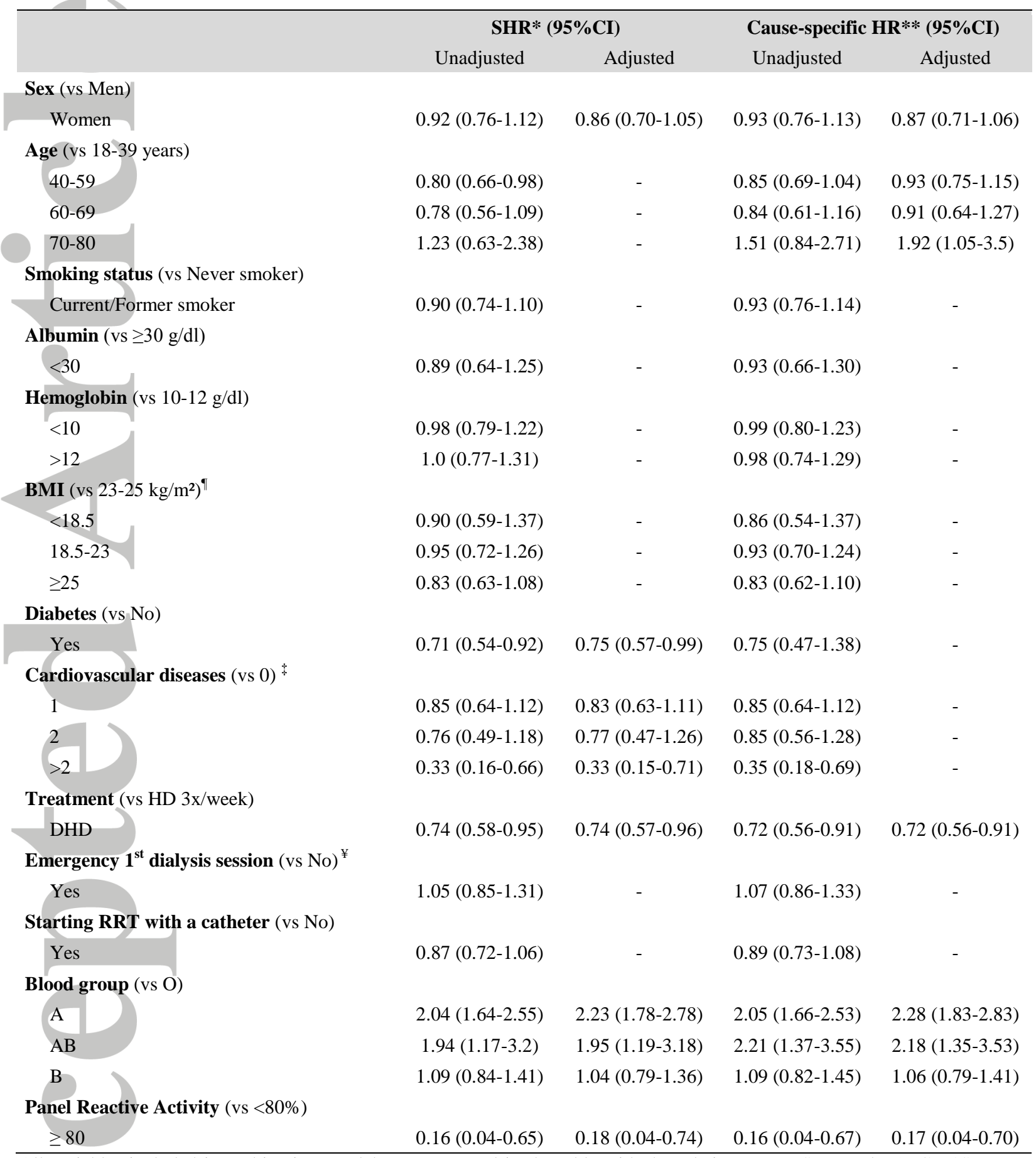

All variables included in multivariate models are presented in the table with the relative HR or SHR and 95\%CI; *SHR:

Subdistribution Hazard Ratio; **HR: Hazard Ratio; ${ }^{\mathbb{I}}$ BMI: Body Mass Index; ${ }^{\star}$ Cardiovascular Disease: myocardial infarction, arrhythmias, coronary insufficiency, heart failure, arteritis of the lower limbs, cerebrovascular accident; ${ }^{*} \mathrm{RRT}$ :

Renal Replacement Therapy 
Table 4. Causes of death by groups: DHD and 3x/week HD (n=827).

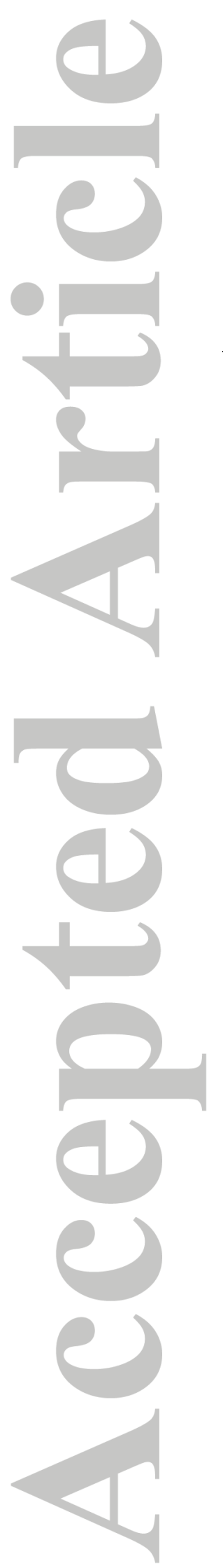

\begin{tabular}{lccc}
\hline & HD 3x/week & DHD & \\
Other & $\mathbf{n}(\boldsymbol{\%})$ & $\mathbf{n}(\boldsymbol{\%})$ & $\mathbf{p}$ \\
Active malignancy & $95(17.2)$ & $40(14.5)$ & 0.329 \\
Cirrhosis & $58(10.5)$ & $21(7.6)$ & 0.186 \\
Malnutrition & $5(0.9)$ & $4(1.5)$ & 0.474 \\
Unknown & $44(8)$ & $13(4.7)$ & 0.083 \\
Cardiovascular disease & $103(18.7)$ & $67(24.4)$ & 0.056 \\
Infectious disease & $155(28.1)$ & $87(31.6)$ & 0.29 \\
Respiratory disease & $81(14.7)$ & $30(10.9)$ & 0.135 \\
Renal disease & $6(1.1)$ & $10(3.6)$ & 0.012 \\
Total & $5(0.9)$ & $3(1.1)$ & 0.798 \\
\hline
\end{tabular}


Table 5. Factors associated with survival (univariate and multivariate Cox model, $\mathbf{n = 2 2 7 1}$ ).

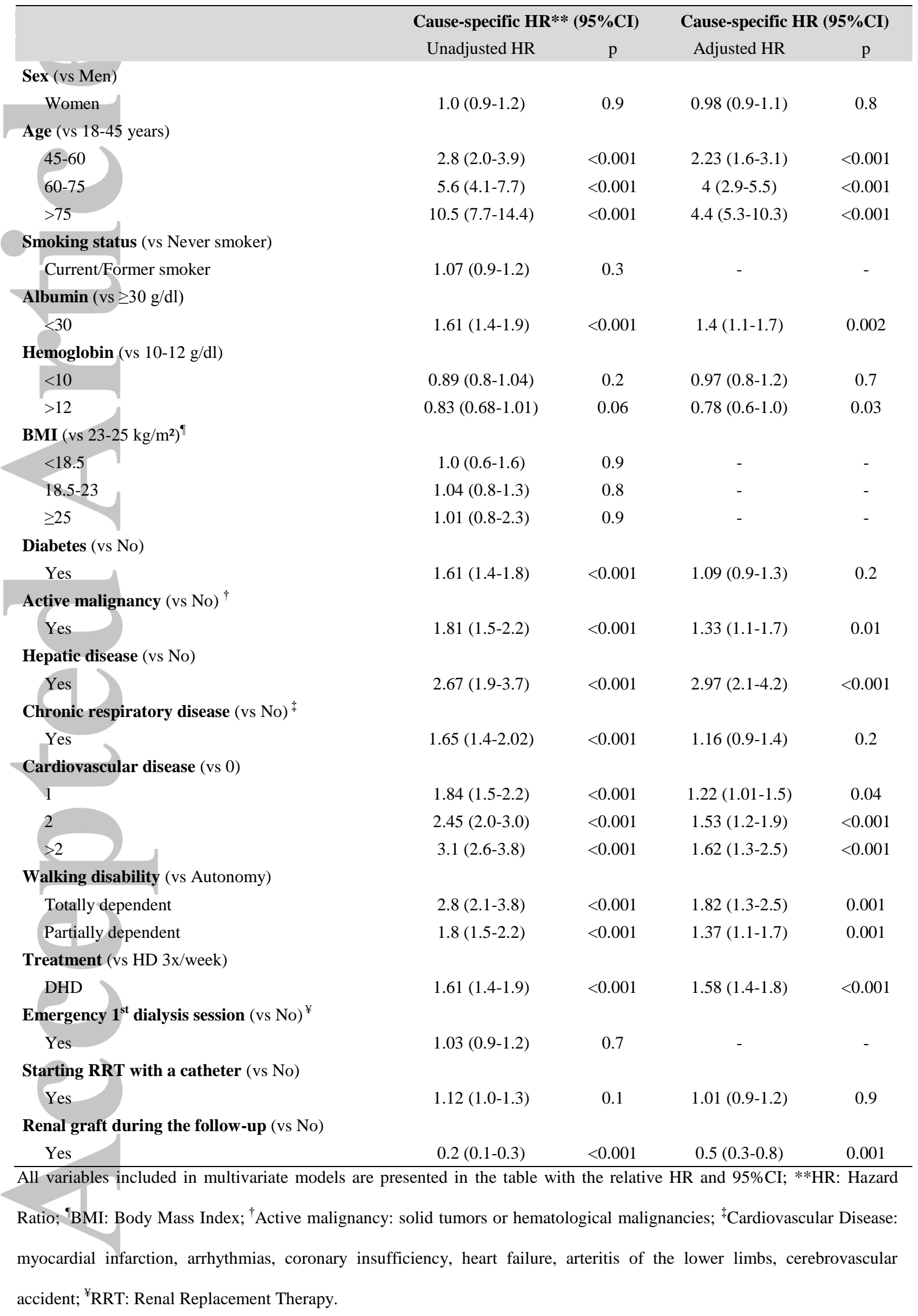




\section{SUMMARY AT A GLANCE}

- This observational study reviewed the association between daily haemodialysis and transplantation and survival in France.

The likelihood of undergoing transplantation after being waitlisted was lower for patients on daily haemodialysis compared to thrice-weekly haemodialysis. Additionally, daily haemodialysis was associated with higher risk of death, even after taking into account age and co-morbidities.
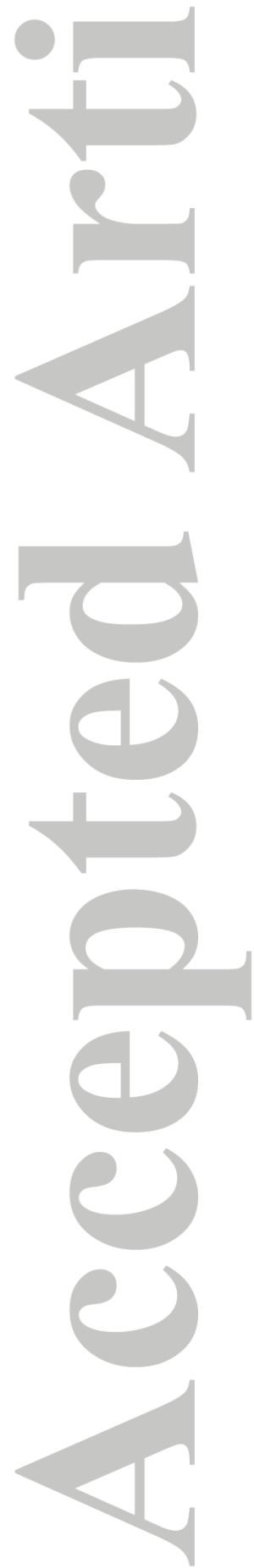